\title{
Adaptive Reuse and Sustainability Protocols in Italy: Relationship with Circular Economy
}

\author{
Gaballo Marika *(D), Mecca Beatrice (D) and Abastante Francesca (D) \\ Interuniversity Department of Regional and Urban Studies and Planning (DIST), Politecnico di Torino, \\ Viale Mattioli 39, 20125 Turin, Italy; beatrice.mecca@polito.it (M.B.); francesca.abastante@polito.it (A.F.) \\ * Correspondence: marika.gaballo@polito.it
}

Citation: Marika, G.; Beatrice, M.; Francesca, A. Adaptive Reuse and Sustainability Protocols in Italy: Relationship with Circular Economy. Sustainability 2021, 13, 8077.

https://doi.org/10.3390/su13148077

Academic Editor: Adriana Del Borghi

Received: 27 May 2021

Accepted: 13 July 2021

Published: 20 July 2021

Publisher's Note: MDPI stays neutral with regard to jurisdictional claims in published maps and institutional affiliations.

Copyright: (c) 2021 by the authors. Licensee MDPI, Basel, Switzerland. This article is an open access article distributed under the terms and conditions of the Creative Commons Attribution (CC BY) license (https:// creativecommons.org/licenses/by/ $4.0 /)$.

\begin{abstract}
This paper explores the enhancement of adaptive reuse (AR) of buildings through the lens of the sustainability protocols within the context of circular economy (CE) in Italy. Cities and the built environment can play a key role in the transition to a $\mathrm{CE}$, especially considering the documented negative global impact due to resource consumption and waste generation. This is recognised among the principles of circularity defined by the European Commission towards a general strategy for a sustainable built environment, which encourages initiatives of building reuse and land consumption reduction. It has been proven that the AR of vacant buildings can bring environmental, social, and economic benefits towards an urban strategy based on CE principles by generating useful values to support innovative development dynamics. In this perspective, the sustainability protocols can be identified as useful tools to pursue strategies for spreading the culture of sustainable build environment. Considering the huge vacant Italian architectural heritage, this paper aims to analyze how the most widely used sustainability protocols in the Italian context currently address the enhancement of the reuse of buildings, to improve environmental, social, and economic quality in the built environment. We discuss the results highlighting how and which sustainability protocols better intercept these issues, providing grounds for future development.
\end{abstract}

Keywords: circular economy; adaptive reuse; sustainability protocols; vacant buildings

\section{Introduction}

Cities and the built environment can play a key role in the transition to a circular economy (CE), especially considering the documented negative global impact of resource consumption and waste generation. Concerning the concept of $\mathrm{CE}$, the European Green New Deal launches a comprehensive strategy focused on a climate neutral and resourceefficient economy, whose action plan aims precisely at providing a legislative initiative for the development of a CE that stimulates investment growth and reduces consumption [1]. In this sense, the shift from a traditional linear economy model to a circular one contributes significantly to achieving climate neutrality in 2050 and decoupling economic growth from resource use [2].

The concept of CE is currently at the core of a scientific discussion [3] and plans to cover the entire economic cycle, namely production, repair, regeneration, and waste management. Among the principles of sustainability and circularity promoted in the action plan we observe [1]: (i) the focus on product durability, reusability, and reparability; (ii) the increase in the use of safe and high-performance recycled materials; (iii) the promotion of high-quality remanufacturing and recycling with a view to limiting single use and premature disposal; (iv) the reduction in environmental impacts.

In this context, the role of the built environment is fundamental to achieving the principles of circularity relating to the entire life cycle of buildings [4,5]. Consider, for example, the need to design durable and adaptable buildings, with supporting digital registers, and the imperative to reduce soil sealing by reactivating abandoned or unused 
buildings, sites and areas [2]. Related to the latter we stress the fact that most of the existing building stock will still be there in the next 100 years and, as such, its sustainable use must be maximised [6,7].

In favour of the development of $\mathrm{CE}$ initiatives, this paper is focused on the adaptive reuse (AR) approach of underused or abandoned buildings, sites, and areas as a useful practice to generate new values by supporting innovative development dynamics.

$\mathrm{AR}$ is a strategy to improve the environmental, social, and financial performance of a building, site, or area by transforming them from unused objects to ones with a new purpose [6-9]. Indeed, adaptability is considered among the general principles for the design of circular buildings in the perspective of extending their life, preventing their premature demolition, through the provision of transformations and adaptations for new uses [10].

In this context, the sustainability protocols can be identified as useful tools to pursue strategies for spreading the culture of sustainable building. In fact, such protocols are identified as a potential economic incentive lever among the ten policy levers suggested by the Ellen MacArthur Foundation (EMF), with a view to designing, assessing, and certifying the sustainability of the built environment through a system of performance criteria [11-13].

Within this framework, the present paper aims at exploring and understanding if and how the most widely used sustainability protocols in Italy (GBC and ITACA), currently address and enhance the practice of AR of underused or abandoned buildings in the broader context of CE. This issue is particularly relevant for the Italian territory, that counts a huge underutilised and abandoned architectural heritage [14,15].

There is huge underutilised and abandoned architectural heritage available within the Italian territory $[14,15]$, this paper explores how it can be reused.

Accordingly, the paper is organised as follows. Section 2 outlines the methodology and the research tasks that were conducted to achieve the objective of this paper; Section 3 explores the role of the sustainability protocols in relation to the concept of the AR framed within the broader context of the CE, providing a description of the most widely used Italian protocols; Section 4 illustrates the results of the analysis; and Section 5 provides the discussion highlighting how and which sustainability protocols better intercept the issues. Finally, Section 6 summarises the conclusions.

\section{Methodology}

The research methodology employed in this paper includes three phases, namely: (i) the intelligence phase, related to the collection of materials and analysis of the key themes and tools of this paper (CE, AR, and the sustainability protocols); (ii) the categorisation phase, related to an in-depth analysis of the protocols in terms of the proposed criteria and credits; (iii) the synthesis phase that aims to provide a framework of results useful to understand the potential shortcomings in the sustainability protocols with respect to the investigated themes (Figure 1). 


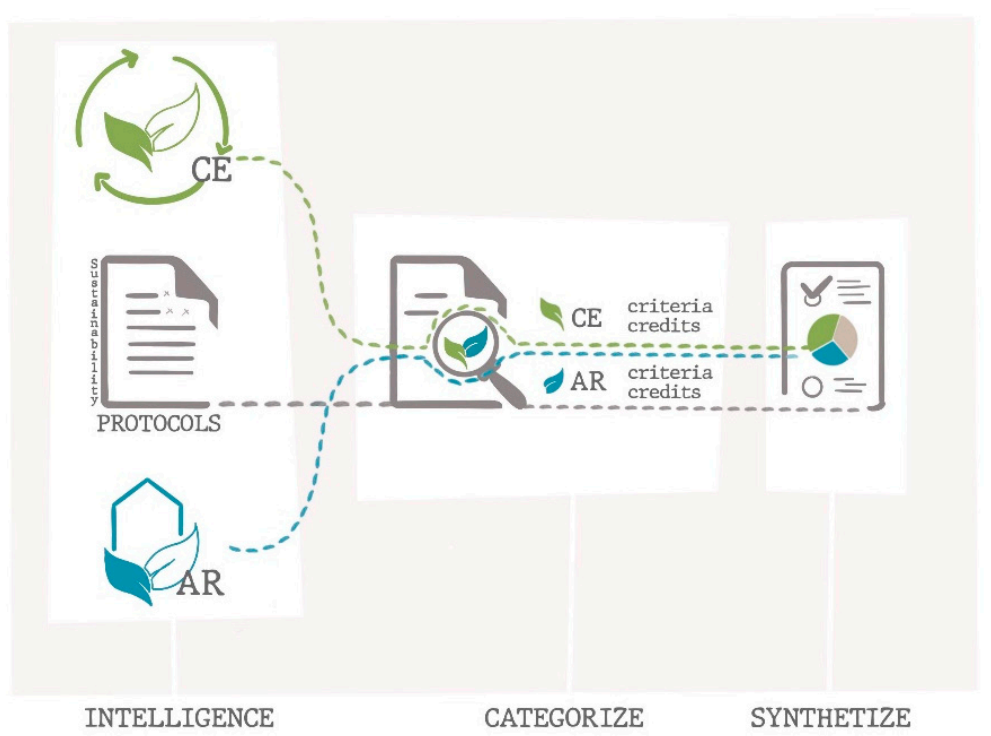

Figure 1. Outline of the 3 steps that compose the linear methodological process of the paper.

\section{Phase 1: Intelligence}

This phase is an exploratory investigation of the concepts and tools underlying the study. This is fundamental in order to provide an appropriate theoretical background on the nexus between the concepts of $\mathrm{CE}$ and $\mathrm{AR}$ and on the role of the sustainability protocols. First, the scientific literature was analysed with respect to the topic of $C E$ in the built environment. Second, the official reports of the European Commission and the EMF were examined to verify the general requirements and principles at European level. Third, the literature concerning the practice of AR was analysed to understand the benefits that it can offer to the transition towards a circular built environment from a social, environmental, and economic point of view. Finally, sustainability protocols were analysed as tools with a potential effective role in achieving circular cities and buildings. Starting from a general framework of these assessment tools with respect to the international panorama, the analysis foresees the identification of the most used sustainability protocols at Italian level and focused on the building scale.

\section{Phase 2: Categorise}

Here, the protocols selected in the previous step are subject to an in-depth review. In this sense, the most used protocols at the Italian level at the building scale are analysed in terms of their contents and more specifically concerning the key elements of the sustainability assessment in terms of proposed criteria and credits. The categorisation of the latter is based on two levels, derived from the core themes of the study analysed in the previous step. Thus, the first category responds to the CE theme and, therefore, identifies which criteria and credits support the assessment with respect to the development of circular principles. The second category relies on the previous one and observes which of these criteria and credits promote and enhance the social, environmental, and economic benefits offered by the practice of AR.

Phase 3: Synthetise

The last methodological step includes the synthesis of the previous in-depth analysis. Accordingly, it is foreseen to provide, through charts and percentage data, a framework of results that allow to understand the potential shortcomings, and, therefore, potential points of implementation of the sustainability protocols analysed, with respect to the themes of $\mathrm{CE}$ and $\mathrm{AR}$.

\section{Theoretical Background}

\subsection{Adaptive Reuse and Circular Economy: The Role of the Sustainability Protocols}

The EMF defines the $\mathrm{CE}$ as "a continuous positive development cycle that preserves and enhances natural capital, optimises resource yields, and minimises system risks by 
managing finite stocks and renewable flows. It works effectively at every scale. The circular economy provides multiple value-creation mechanisms that are decoupled from the consumption of finite resources" [16] p. 46 and circular cities as systems that "embeds the principles of a circular economy across all its functions, establishing an urban system that is regenerative, accessible and abundant by design. These cities aim to eliminate the concept of waste, keep assets at their highest value at all times, and are enabled by digital technology. A circular city seeks to generate prosperity, increase liveability, and improve resilience for the city and its citizens, while aiming to decouple the creation of value from the consumption of finite resources" [17] p. 7. In this sense, the built environment must focus on closed and non-linear circuits, centred on recovery and recycling, pursuing a responsible use of resources while keeping human needs and well-being central to the design.

Adaptive reuse is considered a valuable approach to reactivate and reuse disused or abandoned buildings, sites, or areas giving them a new purpose useful to the society $[6,8,15,18]$. The reuse of this heritage has a positive impact on urban sprawl and land consumption [19], in addition to being defined as an effective and environmentally responsible approach $[6,20,21]$ it also acts with a great impact on cities and territory from an economic and social point of view [22-24]. In this sense, being a form of sustainable regeneration that extends the life of the existing heritage, its key role in the concept of CE within the construction sector is evident [23-27].

CE principles must permeate all stages of a building cycle, transforming the way they are designed and maintained over time by reducing the production of new construction and urban land use $[4,5]$. It is worth mentioning that research on the application of CE to the built environment results to be highly focused on the reduction and recycling of construction waste [28] and that from the EMF and European Commission Action Plan reports there is a strong emphasis on the choice of materials and the way in which new buildings are designed in the perspective of future reuse, while the practice of reusing existing buildings, although promoted and encouraged in favour of reducing soil sealing, appears to be less explored. Indeed, the real estate and construction sector is very focused on designing new buildings that facilitate future circularity [3]. Among the practices promoted on new buildings we observe [29]: (i) modularity and movable walls with a view to a flexible design that allows future incremental changes over time; (ii) the careful and safe selection of construction materials used with a view to future reuse and in favour of the local economy; (iii) design inspired by nature to create energy and technology efficient solutions.

AR as a key element of the CE concept and in line with the concept of sustainable architecture [30] emerges as a widely growing practice in favour of the three pillars of sustainability [23]. Indeed, it offers the following social, environmental and economic benefits:

- From a social point of view, it strengthens the sense of community by promoting the preservation of architectural aesthetics and tangible and intangible values [23,28,31]. Furthermore, reactivating unused or abandoned assets by returning them to architectural, energy, and technological quality promotes the well-being and safety of users and the community [23];

- The environmental sustainability of the reuse practice lies mainly in the lower consumption of energy and new materials, thus in the reduction in emissions and soil sealing $[19,21,32]$;

- Finally, from an economic point of view, two main benefits can be observed, the economic convenience of reuse compared to the demolition and construction of a new building [8,22,33-36] and the positive externality produced on the real estate value of the building itself and adjacent assets, with consequent activation of social and economic flows [23].

New and existing underused or abandoned buildings, if kept efficient, can be reused for more than a century, adapted and reconfigured for new purposes and functions, fos- 
tering the development of a thriving and resilient built environment. In the light of the above, we understand the relevance of the AR approach for economic growth, social wellbeing and environmental conservation: the reuse of underutilised or abandoned heritage contributes to return new opportunities to these assets, decoupling growth from resource consumption [25].

As in new construction, AR projects have a life cycle made of different phases, namely planning, design, construction, and operation and maintenance [22]. Within such projects several professionals are involved (architects, engineers, contractors, and facility managers) on the effectiveness of the practice and have different roles within the context of architecture, engineering, construction, and facilities management (AEC/FM). In this regard, there is a need for a standardised methodology that unifies professionals [37] helping them "speaking the same language". However, before being able to provide detailed recommendations, it is fundamental to first analyse the evaluation tools, such as sustainability protocols, identified as instruments with a potential effective role in the realisation of circular cities and buildings.

We believe that the evaluation tools as sustainability protocols are relevant for this analysis considering the importance of responsible approaches to the built environment to outline tools to assess its sustainability [38]. Actually since the end of the 1980s, within the international context an increasing awareness related to the relationship between the need for new space and its limitation occurred, emphasizing the depletion of this resource although necessary [13]. As a consequence, the research activity in the field of in the field of evaluating the environmental performance of buildings has increasingly highlighted the importance of considering and disseminating responsible practices, leading to the gradual emergence of the need for targeted tools to assess the sustainability of the built environment [37].

With this perspective, in 1990 the first sustainability protocol building research establishment environmental assessment method (BREEAM) was developed by the Building Research Establishment (BRE) organisation in the United Kingdom (Shan and Hwang, 2018), followed 3 years later by the leadership in energy and environmental design (LEED) protocol, developed by the United States Green Buildings Council (USGBC) and quickly became the most widely used sustainability protocol within the international context $[13,37]$. The testing of the BREEAM and the LEED sustainability protocols quickly led to a diffusion of these tools within the international panorama and a consequent development by countries of a reference sustainability protocol at the national level [13].

These tools aim at spreading a sustainable approach towards construction [37] by evaluating through a rating system the application of effective strategies reducing the impact of the construction sector in cities [37,39].

In particular, it is worth noting that the sustainability protocols have evolved over the years since their development [37] by increasingly recognizing the fundamental role of the built environment on people's lives [13]. These tools have shifted from a focus on resource exploitation in energy-environmental terms to a broader perspective, in order to consider different criteria to assess the multidimensionality of sustainability considering the built environment [40]. Indeed, since the early 2000s, there has been a progressive recognition within the sustainability protocols of the need to consider the impacts of the built environment in a more holistic manner [41], paying particular attention to production and responsible approaches towards materials and values [12] and recognizing the role of the construction sector on both environmental, economic, and social issues [42,43].

In this perspective, the potential role of the sustainability protocols in the effective pursuit of more circular cities seems evident [16], considering not only the design of new buildings, but also in the management of the existing building heritage through responsible approaches. 


\subsection{The Italian Context}

The phenomenon of abandoned and underused buildings is relevant in Italy, which counts for a total number of unused buildings and dwellings exceeding six million [14,15]. These buildings constitute a symbolic value and significance for the place and the community in terms of historical memory and, therefore, their unique historical and cultural characteristics must be preserved [44].

Hence, with reference to this huge stock of disused or abandoned buildings that cha0racterises the Italian context, it could be interesting to explore how the most used sustainability protocols in Italy address the AR for the improvement of the environmental, social, and economic quality of cities.

The most widely used protocols in Italy include the Green Building Council Italia (GBC Italia) protocol [45], developed in 2009 and the Institute for Transparency of Contracts and Environmental Compatibility (ITACA) protocol [46], developed in 2004 [13].

In particular, the GBC Italia sustainability protocol is an adaptation to the Italian context of the LEED protocol developed in the United States. Moreover, it is a voluntary tool that includes the following four classifications according to the type of its application: the GBC Home, the GBC Neighborhoods, and the GBC Condominiums, considering the residential buildings, and the GBC Historic Buildings [45].

The GBC Italia assessment model is based on a hierarchical system that at the highest level includes thematic sections, containing both mandatory prerequisites and nonmandatory credits to be considered for the assessment [45]. In particular, a score is assigned to the credits based on requirements identified by the credits themselves [13]. Therefore, the level of the certification obtainable from the GBC Italia protocol derives from the sum of the scores of each credit, which, in particular, can vary from a minimum of 40 points to a maximum of 110, diversifying the overall classification into basic, silver, gold, or platinum [45].

Similarly, the ITACA protocol is a voluntary tool contextualised in the Italian context based on the international assessment model SBTool, developed as part of the Green Building Challenge research process [46]. In particular, the ITACA protocol includes three classifications based on its type of application: the ITACA for residential buildings, the ITACA for non-residential buildings and the ITACA Urban Scale [13].

Unlike the GBC Italia protocol, the elements of the assessment model of the ITACA protocol change both in number and content according to the regional application on the Italian territory, since it is strongly context dependent [13].

Moreover, the ITACA protocol also includes a hierarchical assessment model, that considers at the highest level the thematic evaluation areas, which contain the categories deepening the topic covered by the evaluation areas [13]. Furthermore, the categories contain the criteria, delving into an aspect of the category. Finally, the criteria contain the performance indicators, which are useful in assessing the performance of each criterion [45]. In particular, the assessment within the ITACA protocol starts from the performance indicators, to which an absolute value is attributed based on the comparison with benchmarks of the regulatory framework and local building practice [46]. Subsequently, the absolute values are normalised in a range from -1 to +5 and aggregated in order to return the score for each criterion, which is, in turn, aggregated to provide the score of the category. Finally, the scores of each category return the overall score within a range from -1 to +5 , where 0 is considered the standard performance and 3 the best practice [13].

It should be noted that both the GBC Italia protocol and the ITACA protocol have a hierarchical structure starting from the thematic areas deepened by the credits and criteria, which are evaluated according to the use of performance indicators or requirements outlined within the protocol itself. Therefore, within the sustainability protocols examined the level of the credits and criteria provide the key element of the evaluation model [40].

Within the present research, the credits and the criteria, respectively, of the GBC Italia and the ITACA protocols are used as a framework to verify that they address the issues 
related to the enhancement of the reuse of buildings for improving the environmental, social, and economic quality of cities.

\section{Criteria for the Enhancement of Building Reuse}

In this section we provide the categorisation of criteria and credits. Since the in-depth analysis provided in this paper focuses on the building scale to better intercept the AR concept, the GBC Home, GBC Historic Buildings, ITACA for residential buildings, and ITACA for non-residential buildings protocols have been investigated, thus excluding applications that include a larger urban scale.

Subsequently, the selected building-scale applications of the sustainability protocols under consideration were analyzed in detail at the level of the key elements used within the assessment model provided, such as:

- The credits with regard to the GBC Home and the GBC Historic Buildings protocols;

- The criteria for the ITACA for residential buildings and the ITACA for non-residential buildings protocols.

It should be specified that, since the ITACA protocol changes in terms of the number and content of the criteria according to the application within the regional territory, for the purposes of the analysis it was chosen to analyze the ITACA protocol of the Piedmont Region, in northern Italy [47].

In particular, in order to understand how the sustainability protocols examined and addressed the issue of the AR within the broader context of the $\mathrm{CE}$ some phases of analysis have been followed. First, all the 74 credits (GBC) and the 59 criteria (ITACA) of the sustainability protocols under examination were studied in detail in terms of the content in order to categorise these credits and criteria according to the two levels highlighted in Section 2 (see "Attached 1" in Supplementary Material). Second, the credits and the criteria with a relation to the $C E$ were identified. Third, among these credits and criteria, those that addressed the AR were identified. Indeed, within the examined protocols, all the credits and the criteria that relate to the AR also relate to the broader concepts of $\mathrm{CE}$.

Through this in-depth analysis, the credits and the criteria of the examined sustainability protocols which address the AR within the context of the CE were, therefore, identified and selected (Figures 1 and 2).

Figure 2 shows the 33 identified credits out of the total 74 credits of the sustainability protocols GBC Home and Historic Building having a relation to the $\mathrm{CE}$ in terms of investigated contents (see "Attached 1" in Supplementary Material). Accordingly, those identified credits relate mainly on the reduction in consumption and waste of resources and materials, paying attention to natural capital and environmental impacts while focusing both on the promotion of recycling, reuse, and of sourcing from renewable sources.

Moreover, according to Figure 2, among these credits those relating to the AR can be highlighted. In detail, Figure 2 underlines how the GBC Home and the GBC Historic Buildings protocols provide, respectively, 12 and 21 credits related to the $\mathrm{CE}$. Among those identified credits the GBC Home protocols underlines 2 out of 12 credits concerning the AR, compared to the 4 out of 21 credits provided by the GBC Historic Building protocol.

In particular, the credit "Selection of the site" on the one hand in line with the CE concept aims to reduce the environmental impact of buildings by protecting natural capital [17], while on the other hand in line with the AR concept it seeks to re-habilitate an existing building with interventions of architectural upgrading or construction of additional levels on the existing building. In addition, the credit "Reuse of structural and non-structural elements of buildings" also within the GBC Home protocol is in line with the CE concept, aiming to extend the life cycle of the existing building stock, preserving resources and reducing the environmental impact in relation to the production and transport of materials [17]. In parallel, this credit also refers to the AR aiming to reuse the existing building in its major elements considering the load-bearing structure, the building envelope, as well as its internal partitions. 


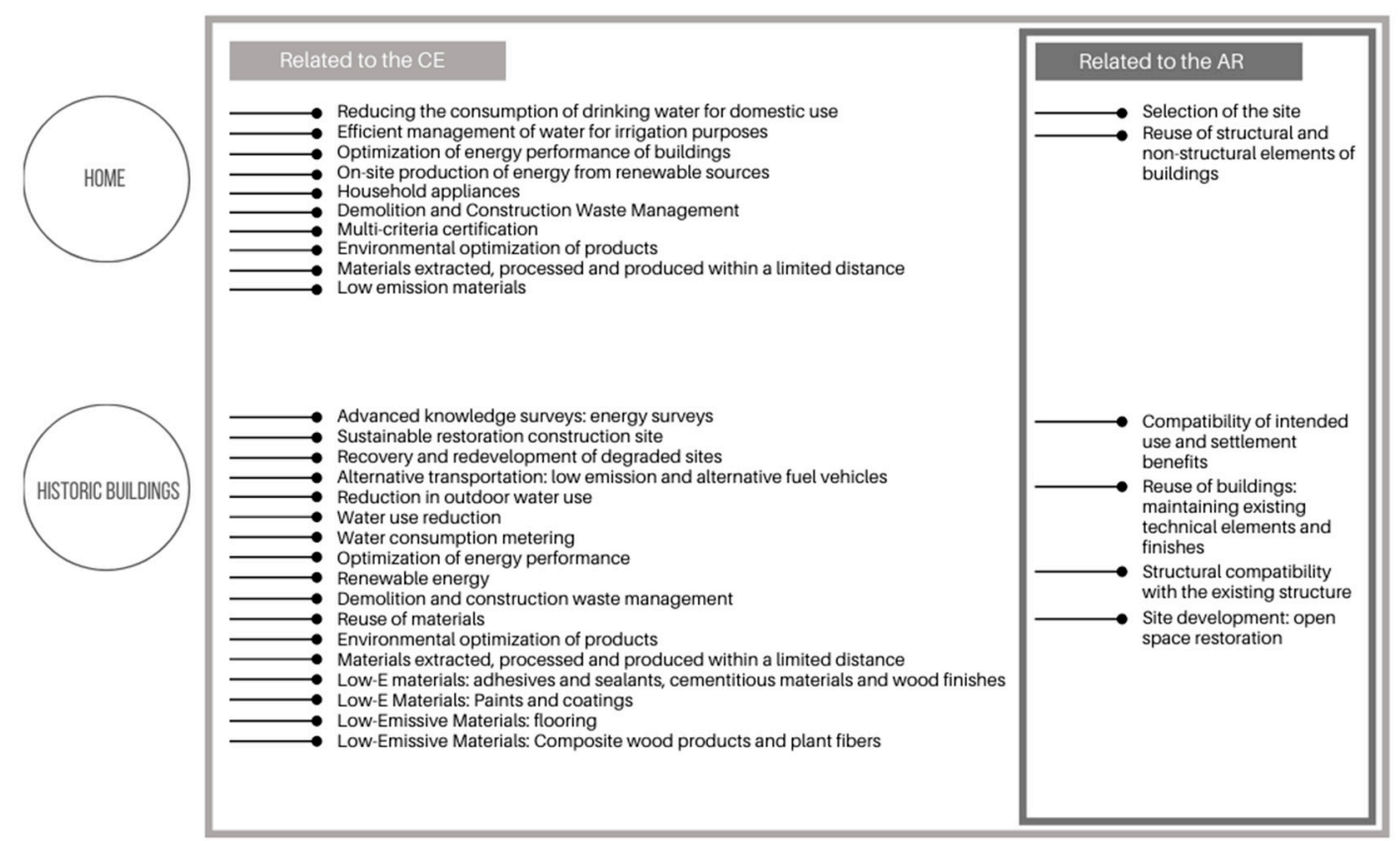

Figure 2. Credits of the GBC Italia Home and the Historic Buildings protocols related to the CE and the AR concepts.

Similarly, Figure 2 shows that according to the GBC Historic Building protocol, the credits concerning the $\mathrm{CE}$ include those related to the AR.

In particular, the "Compatibility of intended use and settlement benefits" and "Reuse of buildings: maintaining existing technical elements and finishes" are in line with the AR approach since evaluate respectively the re-functionalisation of existing historic buildings, with particular attention to identify uses that promote the good conservation over time, and the reuse of buildings in order to extend the life cycle of the existing building heritage, preserving the historical resources in environmental, social, and cultural terms.

Additionally, the credit "Structural compatibility with the existing structure" appears in line with AR (Figure 2), suggesting to minimise the transformation [18] by protecting the compatibility with the existing structure and preserving the shapes and the characteristics of the existing buildings. Furthermore, the possible presence of external spaces annexed to the building can be an issue to be discussed in terms of project scale and the potential of the building. Indeed, these latter represent some of the fundamental points to be investigated in an AR project [18], and, according to this the transformation of the external spaces of the building, should be carefully investigated since they could constitute a positive potential to be exploited or a negative potential to be managed. In this sense, the credit "Site development: open space restoration" (Figure 2) supports the management and the sustainable development of these spaces.

Similarly, according, respectively, to the ITACA protocol for residential buildings and the ITACA protocol for non-residential building Figure 3 shows the 25 identified criteria out of the total 59 criteria having a relation to the CE in terms of investigated content. Indeed, these criteria are mainly related on one hand to waste and efficient management of resources and on the other hand the use of renewable sources and reuse of materials and the use of sustainable materials, aiming to avoid waste.

Moreover, according to Figure 3, among these credits those relating to the AR can be highlighted. In particular, Figure 3 shows how the ITACA protocol for residential buildings and the ITACA protocol for non-residential building provide, respectively, 12 and 13 criteria related to the CE. Among those identified criteria both the ITACA protocols underline 1 criterion concerning the AR. Indeed, within both protocols the criterion "Land reuse" is in line with the CE concept aiming to safeguard and enhance the natural capital [17], while 
it refers to encouraging the reuse of previously anthropised, disused or contaminated areas, in order to avoid the consumption of new land, with reference to both land and buildings.

ITACA

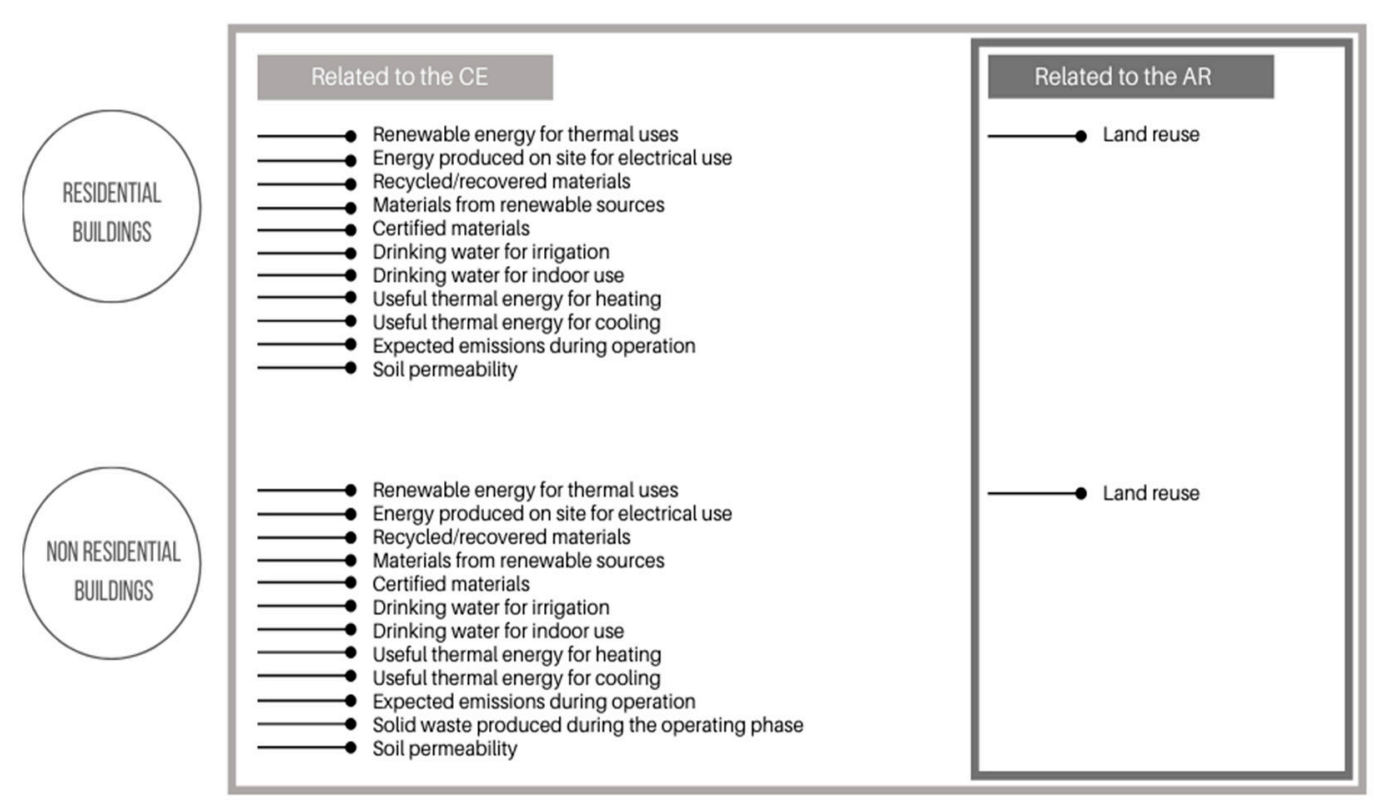

Figure 3. Criteria of the ITACA for residential buildings and for non-residential buildings protocols related to the CE and the AR concepts.

In particular, Figures 2 and 3 show how, respectively, both the credits and the criteria of the sustainability protocols investigated emphasise relationships mostly with the broader concepts of $\mathrm{CE}$ rather than the AR. Indeed, these credits and criteria focus more on the one hand on the reduction in consumption and waste of resources and materials, promoting recycling and reuse, and on the other hand on the promotion of resources from renewable sources. Among those credits and criteria that relate to $\mathrm{CE}$ only a few are identified as relating to the AR (respectively, for 2 out of 12 GBC Home, 4 out of 21 for GBC Historic Building and only 1 for ITACA protocol for residential buildings and the ITACA protocol for non-residential building).

Accordingly, it should be noted in Figure 2 that, according to the GBC Historic Building protocol, the credit "Recovery of degradated sites" refers to the environmental restoration of degraded sites only through remediation and disposal of hazardous waste, having therefore no relation to the AR but only to the $\mathrm{CE}$ concept. Moreover, the credit "Reuse of materials" within the GBC Historic Building (Figure 2) refers only to the reuse of minor materials. Indeed, as explained in the protocol, large functional parts of the building that are reused are not considered within this credit [45]. This is also in line to the "Recycled/recovered materials" and "Materials from renewable resources" of both the ITACA protocols underlines in Figure 3, which including a list of minor materials [46], thus emphasising relations only with the $\mathrm{CE}$.

\section{Discussion of Results}

In order to provide all-encompassing results, in this section we synthetise in which percentage the credits and the criteria of the GBC Italia and the ITACA protocols support the practice of $A R$ affect the totality of the credits and the criteria contained within the assessment framework (Figures 4 and 5). In this way, the crossing of the two analyses provided has allowed to bring to light some interesting considerations. 


\section{GBC Italia}
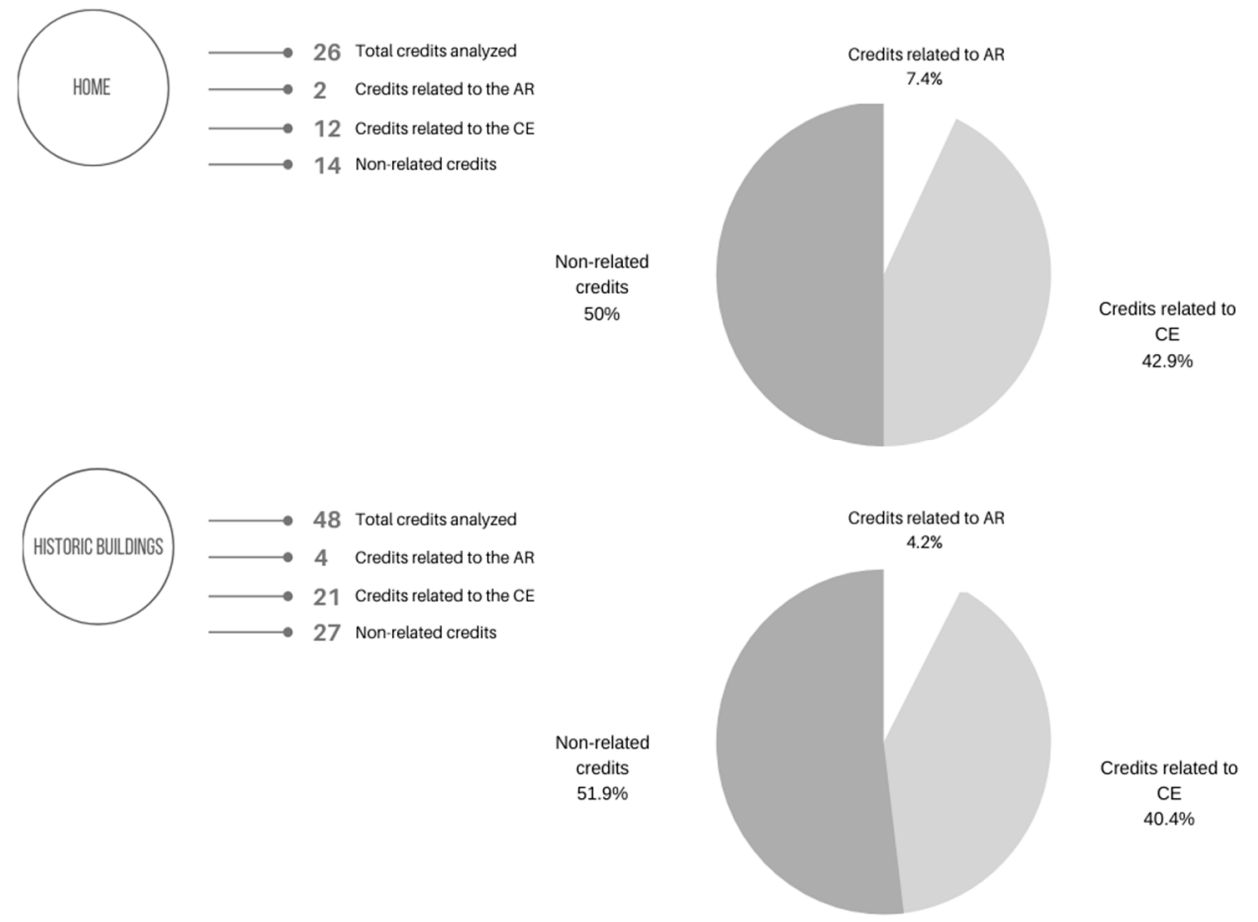

Figure 4. GBC Home and GBC Historic Buildings protocol credits related to AR and CE out of total credits considered.
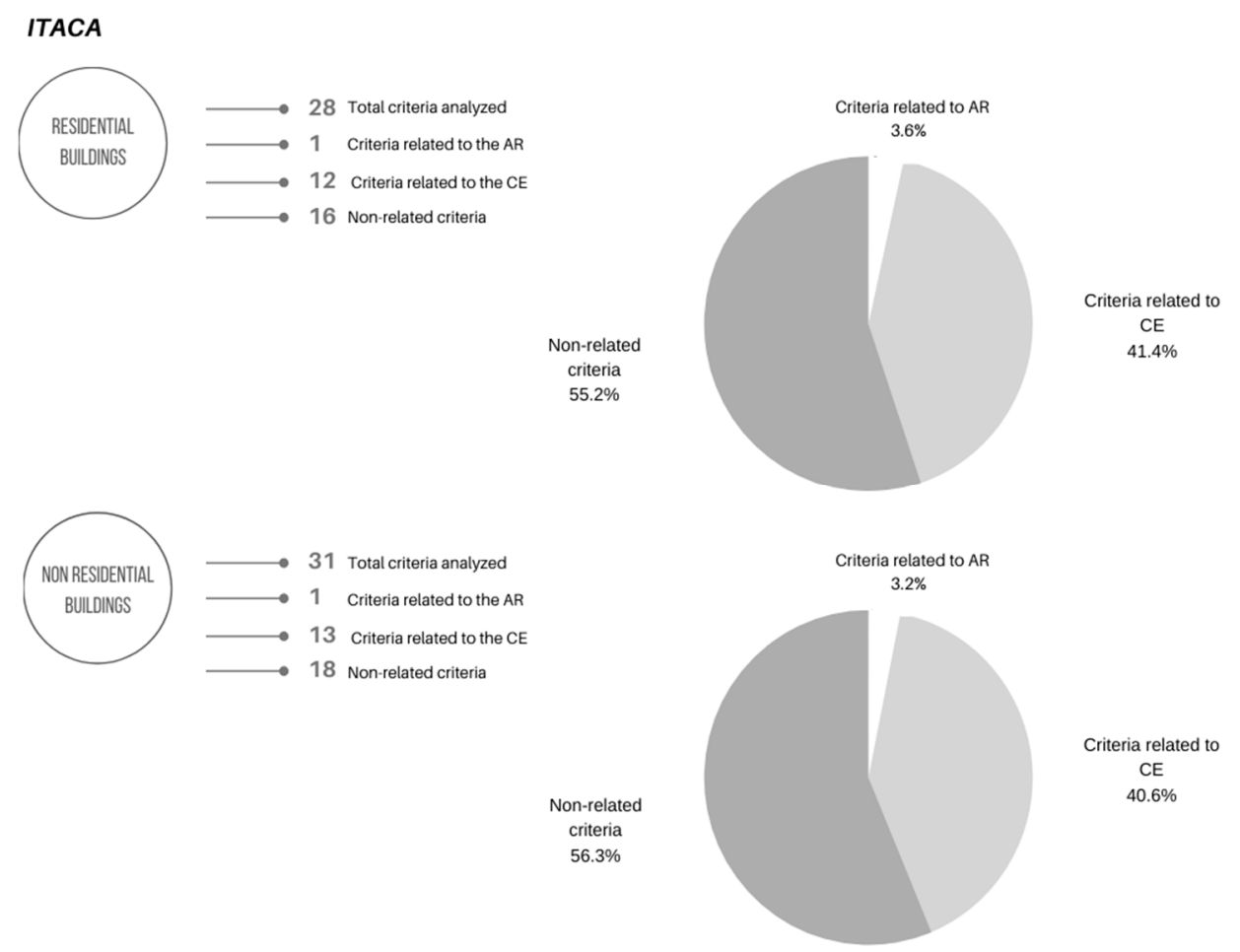

Figure 5. ITACA for residential buildings and for non-residential buildings protocol criteria related to AR and CE out of total criteria considered. 
Figure 4 shows that although in the previous analysis the GBC Historic Buildings protocol seemed to be the one with the most consideration of both the AR and the EC concepts (Figure 2), in consideration of the total number of credits provided within the assessment model the GBC Home protocol contains more credits related to both the AR and the CE (respectively, 2 and 12 out of 26).

In both cases it can be observed that half of the credits considered within the model appear to have no relationship with either the AR or the CE. However, it should be emphasised that in this study only protocols at the building scale were considered, as if sustainability protocols were considered at a larger scale the results may change.

Figure 5 points out that there are no substantial differences highlighted considering the two sustainability protocols ITACA for residential buildings and the ITACA for nonresidential buildings. Accordingly, within these two protocols a similar number of both total criteria and criteria related to the AR and the CE are considered. In particular, also with reference to non-related criteria, the difference is not substantial. Indeed, in the case of the ITACA protocol for residential buildings there are 16 non-related criteria out of 28 totals, while the ITACA protocol for non-residential buildings shows 18 non-related criteria out of 31 totals.

From the analysis provided, the GBC Home although it is not the protocol with the highest number of credits related to the AR, as it is the one that considers a lower total number of credits and criteria than the others, it seems to be the one with the percentage of criteria most related to the topic under investigation. In particular, it focuses on one hand on the reuse of the existing buildings through interventions respecting the architectural features with the credit "Selection of the site" and, on the other hand, concerning the credit "structural compatibility with the existing structure" on the evaluation of the percentage of reuse of the building, in terms of preservation of its structural characteristics.

Moreover, it is interesting to note that although the GBC Historic Buildings protocol does not show the highest percentage of credits related to the practice of reuse, it is the one with the highest number of credits related to the AR and with a more holistic approach in reference to both the AR and the CE. Indeed, according to the "Compatibility of intended use and settlement benefits" and "Site development: open space restoration" it shows a particular attention in terms of compatibility of both the uses that preserve the memory and the historical and cultural significance of the buildings, and on the sustainable regeneration of the site and the location of the buildings, generating environmental, economic and social benefits. Within this sustainability protocol is in fact emphasised a particular attention towards the recognition and the enhancement of historical heritage, both in terms of reuse and enhancement of its significant features on the territory [48]. Instead, concerning the "Reuse of buildings: maintaining existing technical elements and finishes" and "Structural compatibility with the existing structure" credits, the GBC Historic Buildings protocol considers more technical and structural issues in order to preserve the forms and characteristics of the assets under transformation.

Furthermore, the ITACA protocols for residential buildings and the ITACA for nonresidential buildings are those with fewer criteria related to the practice of reuse, mainly focused on a reuse in terms of decreasing of the land consumption, not considering issues related to the measurement of respect for architectural features of buildings, the flexibility and modularity of the space, nor the preservation of memory and historical or cultural significance.

\section{Conclusions and Future Developments}

This paper analyses the most widely used sustainability protocols in Italy, GBC Italia and the ITACA protocols, to explore how AR of underused or abandoned buildings is addressed within the broader context of CE. AR presents itself as a valuable approach to reactivate and reuse disused or abandoned buildings, sites or areas, giving them a new useful purpose. It is therefore identified as sustainable regeneration and as such we recognise its key role in the concept of a CE. 
The EMF emphasises the fundamental role played by cities within the consumption and exploitation of resources, since they are the main drivers of economic and social development [17]. Accordingly, within cities the construction sector plays an important role for sustainability purposes, being responsible for a strong impact on the environmental, economic, and social spheres [49].

In order to analyse and understand how this practice is considered and promoted within the sustainability protocols, an in-depth analysis has been carried out in which the credits and the criteria respectively of the GBC Italia and the ITACA protocols are used as a framework to verify if they are able to address the issues related to the enhancement of the reuse of buildings for improving the environmental, social, and economic quality of cities.

Specifically, we analyzed the GBC Home, the GBC Historic Buildings, the ITACA for residential buildings and the ITACA for non-residential buildings protocols.

The results of the analysis show that both the ITACA protocols present little relationship in terms of consideration of the practice of reuse, compared to the GBC Home and the GBC Historic Buildings protocols. This may be due to the fact that the GBC Italia protocol is a declination to the Italian context of the LEED protocol, within which the consideration of reuse of the built heritage is emphasised, considering in particular the $\mathrm{AR}$ and the preservation as an added value within projects. At the same time, the ITACA protocol focuses heavily on resource consumption, especially in terms of land use and energy, providing a limited model to measure performance in terms of AR.

It is worth highlighting two relevant elements according to the practice of AR: first, in the report of the EMF and in the action plan the AR of existing buildings seems to take a back seat to the sustainable and circular design of new buildings for future reuse; second, even national sustainability protocols seem to be less related to AR in terms of evaluation credits and criteria, in favour of a greater promotion and assessment of CE issues, such as resource consumption and waste production. This is probably due to the fact that, as Foster [24] states, although AR demonstrates environmental, social, and economic benefits, it does not necessarily lead to a complete reduction in the need for new buildings or require more impactful practices than new construction due to outdated or contaminated buildings that may not be up to current standards. Thus, we can conclude that AR supports and represents a key and fundamental component in the transition towards a CE, allowing the reactivation of the disused or abandoned Italian architectural heritage and reducing consumption, waste production, and soil sealing, but above all this practice must be taken into account when designing new buildings for a future circular and reusable built environment. On the basis of the results, we stress that both the sustainability protocols considered should include a broader set of credits and criteria to support AR on both existing and new buildings in the perspective of future reuse.

It is important to underline that the research so far conducted leaves room for future development. First, we plan to broaden the research perspective to include so-called neighbourhood-scale sustainability protocols. The concept of the CE is broad and it would be useful to understand to what extent the overall sustainability protocols respond to it.

Second, a substantive analysis of the evaluation methods for the individual criteria and credits would be appropriate in order to ascertain whether they are appropriate from the point of view of the CE and AR or whether they need to be rethought or revised.

Finally, it would be interesting to identify the different advantages and recommendations for the actors involved in the design process, with respect to the application of sustainability protocols in AR contexts. An in-depth analysis of the application dynamics of protocols from the perspective of $\mathrm{CE}$ and AR would provide a set of useful guidelines for practitioners.

Supplementary Materials: The following is available online at https:/ / www.mdpi.com/article/10 .3390/su13148077/s1, Attached 1: Credits and Criteria of the GBC Italia and ITACA protocols related to $\mathrm{AR}$ and $\mathrm{CE}$ concepts. 
Author Contributions: Conceptualisation and supervision A.F.; Methodology, investigation, writing-original draft preparation, G.M. and M.B.; Writing—review and editing, A.F., G.M., and M.B. All authors have read and agreed to the published version of the manuscript.

Funding: This research received no external funding.

Institutional Review Board Statement: Not applicable.

Informed Consent Statement: Not applicable.

Data Availability Statement: The data presented in this study are available in this article "Adaptive Reuse and Sustainability Protocols: relationship with Circular Economy" and in the Supplementary Material "Attached 1: Credits and Criteria of the GBC Italia and ITACA protocols related to AR and CE concepts".

Conflicts of Interest: The authors declare no conflict of interest.

\section{References}

1. European Commission. Circular Economy Action Plan. For a Cleaner and More Competitive Europe. 2020. Available online: https:/ / op.europa.eu/en/publication-detail/- / publication/45cc30f6-cd57-11ea-adf7-01aa75ed71a1/language-en/formatPDF/source-170854112 (accessed on 14 April 2021).

2. European Commission. Communication From the Commission to the European Parliament, the Council, the European Economic and Social Committee and the Committee of the Regions. A New Circular Economy Action Plan For a Cleaner and More Competitive Europe. 2020. Available online: https:/ / eur-lex.europa.eu/legal-content/IT/TXT/?uri=CELEX\%3A52020DC0098 (accessed on 14 April 2021).

3. Kyro, R.K. Share, Preserve, Adapt, Rethink-A focused framework for circular economy. IOP Conf. Ser. Earth Environ. Sci. 2020, $588,1.11-1.14$. [CrossRef]

4. Ellen MacArthur Foundation and ARUP. Circular Economy in Cities: Project Guide. 2019. Available online: https://www. ellenmacarthurfoundation.org/publications/circular-economy-in-cities-project-guide (accessed on 16 April 2021).

5. Ellen MacArthur Foundation and ARUP. Urban Buildings System Summary. 2019. Available online: https://www. ellenmacarthurfoundation.org/assets/downloads/Buildings_All_Mar19.pdf (accessed on 16 April 2021).

6. Bullen, P.A.; Love, P.E.D. Factors influencing the adaptive re-use of buildings. J. Eng. Des. Technol. 2011, 9, 32-46. [CrossRef]

7. Abastante, F.; Lami, I.M.; Mecca, B. How covid-19 influences the 2030 Agenda: Do the practices of achieving the sustainable development goal 11 need rethinking and adjustment. Valori Valutazioni 2020, 26, 11-23. [CrossRef]

8. Abastante, F.; Corrente, S.; Lami, I.M.; Greco, S.; Mecca, B. The introduction of the SRF-II method to compare hypothesis of adaptive reuse for an iconic historical building. Oper. Res. Int. J. 2020. [CrossRef]

9. Lami, I.M.; Tavella, E. On the usefulness of soft OR models in decision making: A comparison of Problem Structuring Methods supported and self-organized workshops. Eur. J. Oper. Res. 2019, 275, 1020-1036. [CrossRef]

10. European Commission. Circular Economy. Principles for Buildings Design. 2020. Available online: https://ec.europa.eu/ docsroom/documents/39984 (accessed on 15 April 2021).

11. Ellen MacArthur Foundation. Towards the Circular Economy. Economic and Business Rationale for an Accelerated Transition. 2013. Available online: https:/ / www.ellenmacarthurfoundation.org/assets/downloads/publications/Ellen-MacArthurFoundation-Towards-the-Circular-Economy-vol.1.pdf (accessed on 15 April 2021).

12. Abastante, F.; Lami, I.M.; Mecca, B. How to revitalise a historic district: A stakeholders-oriented assessment framework of adaptive reuse. In Values and Functions for Future Cities; Springer: Cham, Switzerland, 2020; pp. 3-20.

13. Abastante, F.; Lami, I.M.; Gaballo, M. Pursuing the SDG11 Targets: The Role of the Sustainability Protocols. Sustainability 2021, 13, 3858. [CrossRef]

14. Campagnoli, G.; Tognetti, R. L'Italia da Riusare, La Nuova Ecologia. 2016. Available online: http:/ / www.osservatorioriuso.it/ cgi-bin/documentazione/Nuova\%20Ecologia\%20novembre-2016.jpg.pdf (accessed on 15 April 2021).

15. Lami, I.M. Shapes, rules and values. In Abandoned Buildings in Contemporary Cities: Smart Conditions for Actions; Smart Innovation, Systems and Technologies Series; Springer: Cham, Switzerland, 2020; Volume 168, pp. 149-162.

16. Ellen MacArthur Foundation; SUN; McKinsey Centre for Business and Environment. Growth Within: A Circular Economy Vision for a Competitive Europe. 2015. Available online: https:/ / www.ellenmacarthurfoundation.org/assets/downloads/publications / EllenMacArthurFoundation_Growth-Within_July15.pdf (accessed on 15 April 2021).

17. Ellen MacArthur Foundation. Cities in the Circular Economy: An Initial Exploration. 2017. Available online: https://www. ellenmacarthurfoundation.org/assets/downloads/publications/Cities-in-the-CE_An-Initial-Exploration.pdf (accessed on 15 April 2021).

18. Robiglio, M. The adaptive reuse toolkit. How cities can turn their industrial legacy into infrastructure for innovation and growth. Urban Reg. Policy Pap. 2016, 38, 5-38.

19. De Gregorio, S.; De Vita, M.; De Berardinis, P.; Palmero, L.; Risdonne, A. Designing the Sustainable Adaptive Reuse of Industrial Heritage to Enhance the Local Context. Sustainability 2020, 12, 9059. [CrossRef] 
20. Elefante, C. The greenest building is ... one that is already built. Forum J. 2007, 21, 26-38.

21. Conejos, S.; Yung, E.H.K.; Chan, E.H.W. Evaluation of urban sustainability and adaptive reuse of built heritage areas: A case study on conservation in Hong Kong's CBD. J. Des. Res. 2014, 12, 260-279. [CrossRef]

22. Douglas, J. Building Adaptation, 2nd ed.; Butterworth-Heinemann: Oxford, UK, 2006.

23. Sanchez, B.; Esfahani, M.E.; Haas, C. A methodology to analyze the net environmental impacts and building's cost performance of an adaptive reuse project: A case study of the Waterloo County Courthouse renovations. Environ. Syst. Decis. 2019, 39, 419-438. [CrossRef]

24. Foster, G. Circular economy strategies for adaptive reuse of cultural heritage buildings to reduce environmental impacts. Resour. Conserv. Recycl. 2020, 152, 104507. [CrossRef]

25. Gravagnuolo, A.; Fusco Girard, L.; Ost, C.; Saleh, R. Evaluation criteria for a circular adaptive reuse of cultural heritage. BDC Boll. Cent. Calza Bini 2017, 17, 185-215.

26. Foster, G.; Kreinin, H. A review of environmental impact indicators of cultural heritage buildings: A circular economy perspective. Environ. Res. Lett. 2020, 15, 043003. [CrossRef]

27. Sanchez, B.; Rausch, C.; Haas, C.; Saari, R. A selective disassembly multi-objective optimization approach for adaptive reuse of building components. Resour. Conserv. Recycl. 2020, 154, 104605. [CrossRef]

28. Gravagnuolo, A.; De Angelis, R.; Iodice, S. Circular Economy Strategies in the Historic Built Environment: Cultural Heritage Adaptive Reuse. In Proceedings of the STS Conference, Graz, Austria, 6-7 May 2019.

29. Ellen MacArthur Foundation and ARUP. Designing Buildings for Adaptable Use, Durability and Positive Impact. 2019. Available online: https:/ / www.ellenmacarthurfoundation.org/assets/downloads/2_Buildings_Designing_Mar19.pdf (accessed on 16 April 2021).

30. Permata, D.D.; Kuswandy, A.S.; Riza, A.I.; Sakti, P.F.; Diana, T.I. The centrum-bandung: Adaptive reuse at heritage building as sustainable architecture. IOP Conf. Ser. Earth Environ. Sci. 2020, 409, 012036. [CrossRef]

31. Kıran Çakır, H.; Aydın, D.; Arabulan, S. Adaptive reuse of open spaces in historical buildings. Int. J. Build. Pathol. Adapt. 2020, 38, 703-719. [CrossRef]

32. Young, E.H.K.; Chan, E.H.W. Implementation challenges to the adaptive reuse of heritage buildings: Towards the goals of sustainable, low carbon cities. Habitat Int. 2012, 36, 352-361. [CrossRef]

33. Bullen, P.A.; Love, P.E.D. Adaptive reuse of heritage buildings. Struct. Surv. 2011, 29, 411-421. [CrossRef]

34. Remøy, H.T.; Van der Voordt, D.J.M. A new life: Conversion of vacant office buildings into housing. Facilities 2007, 25, 88-103. [CrossRef]

35. Kohler, N.; Yang, W. Long-term management of building stocks. Build. Res. Inf. 2007, 35, 351-362. [CrossRef]

36. Oppio, A.; Bottero, M.; Ferretti, V. Designing adaptive reuse strategies for cultural heritage with choice experiments. In Appraisal: From Theory to Practice; Stanghellini, S., Morano, P., Bottero, M., Oppio, A., Eds.; Green Energy and Technology Series; Springer: Cham, Switzerland, 2017; pp. 303-315.

37. Hamida, M.B.; Hassanain, M.A. A framework model for AEC/FM knowledge in adaptive reuse projects. J. Eng. Des. Technol. 2020. [CrossRef]

38. Díaz-López, C.; Carpio, M.; Martín-Morales, M.; Zamorano, M. Analysis of the scientific evolution of sustainable building assessment methods. Sustain. Cities Soc. 2019, 49, 101610. [CrossRef]

39. Lazar, N.; Chithra, K. Green Building Rating Systems from the Perspective of the Three Pillars of Sustainability Using Point Allocation Method. In Green Buildings and Sustainable Engineering; Drück, H., Pillai, R., Tharian, M., Majeed, A., Eds.; Springer: Singapore, 2019.

40. Haapio, A.; Viitaniemi, P. A Critical review of building environmental assessment tools. Environ. Impact Assess. Rev. 2008, 28, 469-482. [CrossRef]

41. Zichi, A. Green Protocols for Neighbourhoods and Cities. In Green Planning for Cities and Communities; Springer: Cham, Switzerland, 2020; pp. 302-328.

42. Shan, M.; Hwang, B.-G. Green building rating systems: Global reviews of practices and research efforts. Sustain. Cities Soc. 2018, 39, 172-180. [CrossRef]

43. Illankoon, I.M.C.S.; Tam, V.W.Y.; Le, K.N. Environmental, Economic, and Social Parameters in International Green Building Rating Tools. J. Prof. Issues Eng. Educ. Pract. 2017, 143, 05016010. [CrossRef]

44. Fiorani, D.; Loughlin, K.; Musso, S.F. Conservation-Adaptation, Keeping Alive the Spirit of the Place, Adaptive Reuse of Heritage with Symbolic Value; EAAE: Hasselt, Belgium, 2017; Volume 65.

45. Green Building Council Italia. Regolamento di Certificazione Protocolli a Marchio GBC, Rovereto: GBC. 2019. Available online: https:// www.gbcitalia.org/documents/20182/21329/2019+Regolamento+certificazione+protocolli+GBC+Italia.pdf (accessed on 15 July 2021).

46. Istituto per L'innovazione e Trasparenza Degli Appalti e la Compatibilità Ambientale and Ente Italiano di Normazione. Prassi di Riferimento (UNI/PdR 13.0:2019), Sostenibilità Ambientale nelle Costruzioni-Strumenti Operativi per la Valutazione della Sostenibilità-Inquadramento Generale e Principi Metodologici. 2019. Available online: https://www.ediltecnico.it/wp-content/ uploads /2019/07/UNI21000963_EIT.pdf (accessed on 15 July 2021). 
47. Approvazione e Aggiornamento del Sistema di Valutazione della Sostenibilita' degli Edifici Denominato "Protocollo ITACARegione Piemonte-Edifici". Available online: http://www.regione.piemonte.it/governo/bollettino/abbonati/2018/47/siste/ 00000057.htm (accessed on 15 July 2021).

48. Farjami, E.; Olgaç Türker, Ö. The Extraction of Prerequisite Criteria for Environmentally Certified Adaptive Reuse of Heritage Buildings. Sustainability 2021, 13, 3536. [CrossRef]

49. Moschetti, R.; Mazzarella, L. Protocols for assessment of building sustainability level: A New proposal for the Italian context. AiCARR J. 2015, 31, 54-58. 